AH13183

\title{
Feature
}

Maternity consumer training

B. M. Jenkinson et al.

\section{Effect of a maternity consumer representative training program on participants' confidence and engagement}

Bec M. Jenkinson ${ }^{1,5}$ BEd(Hons), Research Assistant

Joanne Smethurst ${ }^{2}$ BA, MA, Consumer Representative

Rhonda Boorman ${ }^{3}$ BPsych(Hons), PhD Student

Debra K. Creedy ${ }^{3,4}$ PhD, BA(Hons), RN, Adjunct Professor, Professor

${ }^{1}$ Queensland Centre for Mothers and Babies, University of Queensland, St Lucia, Qld 4072, Australia.

${ }^{2}$ Maternity Coalition, c/o Queensland Centre for Mothers and Babies, University of Queensland, St Lucia Qld 4072, Australia. Email: josmethurst@yahoo.com.au

${ }^{3}$ School of Psychology, University of Queensland, St Lucia, Qld 4072, Australia. Email:

r.boorman@uq.edu.au

${ }^{4}$ Griffith Health Institute, Griffith University, Logan Campus, University Drive, Meadowbrook, Qld 4131, Australia.Email: d.creedy@griffith.edu.au

${ }^{5}$ Corresponding author. Email: r.jenkinson@uq.edu.au

Manuscript received 25 September 2013, accepted 27 January 2014, published online dd mmm yyyy

Objective This paper describes the effects of a maternity consumer representative training program on participants' confidence to fulfil this role and engagement in representative activities.

Methods The present study was a descriptive, pre-post evaluation design with a 3-month follow-up. Fiftyeight people completed the program and 55 agreed to participate in the evaluation. Participants completed questionnaires to assess confidence to undertake consumer representative roles and reported on their engagement with consumer activities.

Results Participants' perceived confidence to function in the role of consumer representative differed significantly before and after the workshop $\left(F_{(2,18)}=7.057, P<0.001\right)$, as did confidence in decision making $\left(F_{(2,16)}=7.615, P=0.005\right)$, confidence in negotiating outcomes and liaising with key people $\left(F_{(2,18)}=7.154, P=\right.$ $0.005)$, and confidence in making use of relevant networks $\left(F_{(2,18)}=4.319, P=0.029\right)$. There was a decline in confidence at 3 months, with confidence at this time no longer significantly different from that at the time of 
Publisher: CSIRO; Journal: AH:Australian Health Review

Article Type: research-article; Volume: ; Issue: ; Article ID: AH13183

DOI: 10.1071/AH13183; TOC Head:

recruitment. Engagement with consumer organisations increased by $45 \%$ compared with rates at commencement of the project.

Conclusions The program enhanced participants' confidence to fulfil a maternity consumer representative role but was not sustained. Further research is needed as to how to best support maternity consumer representatives and assess their contribution to promoting woman-centred care.

What is known about the topic? Engaging consumers in the development of health policy, planning, service delivery and review can improve services and health outcomes. There is a serious lack of consumers confident to undertake representative roles. There is a paucity of evidence about the best ways to engage and build capacity among prospective consumer representatives.

What does this paper add? A training program was developed and implemented for prospective consumer representatives in maternity services. Participants reported enhanced confidence to undertake a consumer representative role, but this was not sustained at the 3-month follow-up. The program improved engagement with consumer representative activities.

What are the implications for practitioners? Training and support are essential for effective maternity consumer representation. Programs could involve generic consumer training with additional training offered for specific health services, such as maternity, aged care or mental health. Further attention needs to be given to supporting consumer organisations and consumer representatives in rural and remote areas. There is a significant need for health service committee members to be supported to work effectively with their consumer representatives.

\section{Introduction}

Recent reforms in health generally, ${ }^{1}$ and maternity services specifically, call for greater engagement with consumers. ${ }^{2,3}$ Engaging consumers in the development of health policy, planning, service delivery and review can contribute to a more accessible and acceptable health system and, ultimately, better health outcomes. ${ }^{4}$

There are many forms of consumer and community involvement in health services. Pitkin 5 described three types of consumer representation: (1) formal designation, which involves being elected or nominated by a group as their representative; (2) descriptive representation, where the person is similar (in terms of experiences, health condition etc.) to those being represented but has no formal links to this group; and (3) symbolic representation, where the person and others may view themselves as representing others but may not share the same experiences or needs and have no formal constituency or accountability to others. ${ }^{5}$ This paper focuses on formal consumer representation. According to Nathan et al., ${ }^{6}$ key roles and responsibilities of formal consumer representatives include protecting consumer interests, representing collective views, concerns and issues and fostering two-way communication between their consumer network, the health service and community. 
Publisher: CSIRO; Journal: AH:Australian Health Review

Article Type: research-article; Volume: ; Issue: ; Article ID: AH13183

DOI: 10.1071/AH13183; TOC Head:

There is often ambiguity around the roles of consumer representatives, and the interests of health service staff and consumers are not always aligned. Conflict may emerge due to poor orientation and preparation of consumers for the role, unrealistic expectations by both consumers and staff, lack of support (personal, professional, fiscal and practical, such as child-care for maternity representatives), negative staff attitudes and ineffective preparation of committee chairs to manage meetings with diverse membership and views.

A search of the literature on training offered to consumer representatives found few empirical studies. Previous reviews identified a lack of evaluation on promoting or organising consumer involvement in healthcare. ${ }^{7,10,11}$ Available studies tend to report on patient or consumer involvement in the planning or development of health services rather than consumers formally representing the interests of other consumers in an ongoing way. For example, Nilsen et al. ${ }^{12}$ included only six randomised controlled trials (RCTs) in their Cochrane systematic review on methods of consumer involvement in developing healthcare policy, research, clinical practice guidelines and patient information material. None of the reviewed studies evaluated training and support. ${ }^{12}$

There is a paucity of evidence illuminating the training needs, approach or benefits of training for prospective consumer representatives. In the state of Queensland where the present study was conducted, Health Consumers Queensland (HCQ) conducts generic training for all health consumers, but has not published formal evaluations of their program. The International Association for Public Participation Australasia also offers training programs, ${ }^{13}$ but these are not specific to health. Consumers Health Forum of Australia (CHF) conducts annual workshops for consumer representatives as part of their ongoing consumer representation program. ${ }^{14}$ However, reports on these workshops are largely descriptive and evaluations focus on participants' satisfaction with workshops, rather than seeking to assess the impact of the workshop on participants' confidence or competence as consumer representatives.

The only evidence that offers direction about the training needs of prospective consumer representatives comes from the feedback of other consumer representatives. Participants in CHF workshops identified that the complexity of issues in health care is a barrier to the achievement of good practice in consumer representation. ${ }^{14}$ For example, in maternity services, the core issues of informed consent and right of refusal are ethically and legally complex. This complexity is not readily addressed in current generic training programs for consumer representatives across the many areas of health. The need to develop strategies to manage committee dynamics (such as having a voice or working with dominant members) and the need for ongoing training and support are also reported by consumer representatives. ${ }^{14}$ This paper describes and evaluates the Maternity Consumer Representatives Training (MCRT) program, which aimed to address these issues in a capacity building program specifically for prospective consumer representatives in maternity services. 
Publisher: CSIRO; Journal: AH:Australian Health Review

Article Type: research-article; Volume: ; Issue: ; Article ID: AH13183

DOI: 10.1071/AH13183; TOC Head:

The MCRT program sought to support prospective maternity consumer representatives and consisted of printed and online resources, a 1-day workshop, an online forum, peer-mentoring and practical tasks. The MCRT aimed to develop participants' understanding of: (1) the role of a consumer representative; (2) decision-making processes by committees; (3) how to negotiate outcomes and liaise with key people; and (4) how to make use of relevant networks.

\section{Methods}

A pre-post-intervention design with a 3-month follow-up was used to evaluate the MCRT. The protocol for the evaluation study received approval from The University of Queensland Human Research Ethics Committee.

\section{The MCRT program}

The MCRT was devised through a tripartite collaboration of the Queensland Centre for Mothers and Babies (QCMB), a research centre funded by the Queensland Government, HCQ and a leading maternity consumer group, namely Maternity Coalition (MC).

\section{Recruitment strategy}

The program was advertised via QCMB, HCQ and MC newsletters and social media, local print media and through flyers distributed to local health services. Prospective participants contacted an MCRT facilitator by telephone or email, and were interviewed by telephone to confirm that they met the inclusion criteria for training in that: (1) they were a consumer of maternity services; (2) their primary experience was as a health consumer (not a professional care provider); and (3) they were interested in consumer representation.

\section{Workshops}

The first workshop was held in July 2011 in Brisbane and a further two workshops were held in 2012, in Brisbane (February) and Cairns (March). All three workshops had the same interactive full-day structure, although minor refinements were made on the basis of facilitator and participant feedback. Each workshop involved participants in role plays about committee situations, discussions, individual reflection, activities on how to critically review a document and how to analyse evidence. The workshop focused on key principles such as woman-centred care, evidence-based care, informed consent and maternity services reform, as well as supporting participants to build relationships and expand their networks. Each participant also received a 200-page resource folder, comprising information about consumer representation in Queensland, advice about and samples of evidence, meeting tips and strategies and other background information.

\section{Peer mentorship, coaching and support}

After workshop attendance, participants engaged in a range of ongoing mentoring and support activities, including monthly Skype teleconferences, an email discussion group and access to online 
Publisher: CSIRO; Journal: AH:Australian Health Review

Article Type: research-article; Volume: ; Issue: ; Article ID: AH13183

DOI: 10.1071/AH13183; TOC Head:

support materials. Individuals could also contact each other and the consumer consultant team directly for advice and assistance.

\section{Evaluation}

Evaluation of the training program was undertaken using a questionnaire adapted from the CHF Consumer Representative Self-evaluation Tool. ${ }^{17}$ Items that were originally used for self-reflection were adapted to statements requiring responses on a five-point Likert scale, where 5 was the most favourable rating. For example, an item that invited respondents to reflect on their capacity to make constructive contributions to committees was adapted to ask participants to rate their confidence to make constructive contributions to committees. Participants were asked to self-rate perceptions of confidence across 31 elements of the consumer representative role. For analysis, the 31 elements of consumer representation were grouped into four domains: (1) role of consumer representative; (2) decision making; (3) negotiating outcomes and liaising with key people; and (4) making use of relevant networks.

Participants provided demographic details and completed the self-report questionnaire before the workshop (Time 1), after the workshop (Time 2) and at the 3-month follow-up (Time 3). Face and content validity of the adapted tool were established through a review process by members of the project advisory committee. Suggested changes to wording were made. Internal reliability was tested using Cronbach's $\alpha$ coefficient and resulted in coefficients of 0.94, 0.97 and 0.97 at Times 1, 2 and 3, respectively.

\section{Approach to data analysis}

Statistical analysis was performed using PASW Statistics $18.0 .3,{ }^{18}$ with $\alpha$ set at 0.05 . Analyses included one-way repeated-measures ANOVA, mixed between-within subjects ANOVA, Bonferroni post hoc tests and $t$-tests. Mauchly's test for sphericity was used.

\section{Results}

\section{Participant characteristics}

One hundred and thirty-one individuals expressed interest in the training. Subsequently, 73 people withdrew. Some withdrew when told that participation did not lead to paid employment. Others were unavailable on the nominated training dates. Some prospective participants did not meet the eligibility criteria (because their primary experience was as a care provider, not a consumer). Eighteen people were late withdrawals and could not attend the workshop due to disruptions to childcare arrangements, caring responsibilities for sick family members, changes at work, transport difficulties and a perceived crisis of confidence to perform in the role. Fifty-eight participants from around Queensland completed the program. Fifty-five consented to participate in the evaluation study. 
Publisher: CSIRO; Journal: AH:Australian Health Review

Article Type: research-article; Volume: ; Issue: ; Article ID: AH13183

DOI: 10.1071/AH13183; TOC Head:

Participants had diverse educational, employment and family backgrounds (see Table 1) and a range of previous experiences with maternity services, consumer representation and consumer organisations.

The response rates for survey completion at each time point are summarised in Table 2. At the 3month follow-up, the retention rate was 55\% (30 of 55 participants). An independent samples $t$-test was conducted to investigate the significance of differences (demographic characteristics and confidence levels) between those who completed all evaluations and those who did not. Only income was significantly different $\left(\mathrm{t}_{(47)}=-2.09, P=0.44\right)$, with women who reported higher household incomes being more likely to complete the 3-month follow-up questionnaire. Mauchly's test of sphericity was performed and was not significant on any outcome measure. There were no differences between completers and non-completers in terms of confidence in the role $(P=0.86)$, decision making $(P=0.83)$, negotiation $(P=0.38)$, networking $(P=0.38)$ or engagement in consumer activities $(P=0.76)$.

Repeated-measures ANOVA examined changes in confidence levels from before the workshop (Time 1) to immediately after the workshop (Time 2) and then 3 months after the workshop (Time 3 ). Participants' confidence in perceived ability to function in the role of consumer representative differed significantly between time points $\left(F_{(2,18)}=7.057, P<0.001\right)$. Post hoc tests using the Bonferroni correction revealed that confidence in the consumer representative role increased significantly from Time 1 (mean subscale response $=3.94$ ) to Time 2 (mean subscale response $=4.43$; see Table 3). At the 3-month follow-up, confidence reduced slightly and was no longer significantly different from that at the time of recruitment (mean subscale response $=4.01$ ). A similar pattern emerged for confidence in decision making $\left(F_{(2,16)}=7.615, P=0.005\right)$, with confidence increasing significantly from Time $1($ mean $=3.73)$ to Time $2($ mean $=4.44)$ and reducing Time $3($ mean $=3.79)$. For confidence in negotiating outcomes and liaising with key people $\left(F_{(2,18)}=7.154, P=0.005\right)$, confidence levels increased significantly from Time $1($ mean $=3.76)$ to Time $2($ mean $=4.56)$ and reduced at Time 3 (4.03). Levels of confidence in making use of relevant networks $\left(F_{(2,18)}=4.319, P\right.$ $=0.029)$ increased significantly from Time $1($ mean $=3.93)$ to Time $2($ mean $=4.56)$ and reduced at Time 3 (mean $=4.03)$, but was not statistically significant from recruitment.

\section{Engagement with consumer representative activities}

Engagement with consumer representation increased during the project. At the 3-month follow-up, 24 of $30(80 \%)$ respondents were current members of maternity consumer organisations, up from $45 \%$ at commencement of the project. Thirteen (43\%) respondents had increased their level of activity within consumer organisations. These activities included joining a consumer organisation or regularly attending a consumer forum, whereas others contributed to consumer organisations' submissions in response to draft policy and guideline documents. Furthermore, 15 participants had committee roles 
Publisher: CSIRO; Journal: AH:Australian Health Review

Article Type: research-article; Volume: ; Issue: ; Article ID: AH13183

DOI: 10.1071/AH13183; TOC Head:

within their chosen consumer organisations, at either state or national level. Participants also reported becoming consumer representatives on a range of local and state-level committees.

To examine whether engagement was associated with participant confidence, a mixed betweenwithin subjects ANOVA compared changes in confidence levels at three time points and found no significant interaction between engagement and confidence levels $\left(F_{(2,27)}=2.839, P=0.076\right.$, Wilks' Lambda $=0.83$ ) for participants engaged or not engaged in consumer representative activities. Working as a consumer representative neither protected confidence gains nor exacerbated the decline.

\section{Discussion}

The MCRT program was effective in enhancing participant confidence levels across all four domains immediately following the workshop. However, despite ongoing support, by 3 months participants' reported confidence had declined and was no longer significantly above preworkshop levels.

Although mean ratings across all domains were still higher than preworkshop levels, further research is required on strategies to prepare and engage maternity consumer representatives. The MCRT program provided mentoring and support that was external to the health services where participants fulfilled representative roles. Other studies ${ }^{19,20}$ have highlighted the benefits of health services employing a coordinator to mentor, support and facilitate the work of consumer representatives. Our findings may lend weight to the value of such a role, providing such a role is used to facilitate consumer representation across the health service and is not confined to consumer advisory councils or advisory groups. ${ }^{21}$

The present study was limited by the small sample size, which may reduce the generalisability of the findings. Results also need to be considered with caution because of attrition ( $45 \%$ of study participants) at the 3-month follow-up. Although possible effects of attrition bias were assessed using Mauchly's test for sphericity and were not significant, it is possible that participants who dropped out differed in other ways from participants who returned the follow-up questionnaire. Most participants did stay engaged with the group facilitators, but failed to complete the follow-up questionnaire. This may be related to response burden and the requirement to complete the same questionnaire three times.

There are also inherent challenges associated with conducting and evaluating a training program in the community. With regard to representativeness, the program appealed most to well-educated women who had access to a range of social and financial resources. Some women from rural and remote locations, several Indigenous women and some women experiencing socioeconomic disadvantage were also recruited, but greater representation would have been desirable.

Some participants could not commence or continue in the training program due to challenging life circumstances. This is to be expected in voluntary programs, especially those for parents with young children. Although active steps were taken to enhance retention and motivation to continue, heavy 
Publisher: CSIRO; Journal: AH:Australian Health Review

Article Type: research-article; Volume: ; Issue: ; Article ID: AH13183

DOI: 10.1071/AH13183; TOC Head:

caring responsibilities may have precluded engagement. Long-term engagement in consumer representation may be a better indicator of effectiveness of the program rather than assessing engagement when a person has significant caring responsibilities while their child is an infant.

Poor access to technology (especially related to the reliability of participants' Internet services) was a barrier to providing support and mentorship for some participants. The lack of ongoing engagement in Web-based activities by nearly half the group may have contributed to declining levels of confidence at the 3-month follow-up.

The project may have also been limited in our selection of outcome measures. In the absence of available standardised measures for consumer representative confidence, we drew on a set of established indicators and converted those to a self-rating scale. We sought to measure changes in participants' perceptions of confidence, rather than the more complicated concept of competence. Further investigation evaluating training approaches could focus on competence as an outcome. Other evaluations of the effectiveness of consumer representation ${ }^{22}$ have pointed to the need for 'broad indicators of success that include both process and outcome measures'. In keeping with this, other indicators from the study's findings (such as the documented increase in engagement with consumer representation) may also be considered evidence of the value of the MCRT program.

The project revealed lessons about the most successful channels for recruiting prospective consumer representatives. Participants most likely to engage with the project and become consumer representatives were those who self-selected, rather than being sought. This finding is relevant both for recruitment to future training opportunities and also to organisations seeking to recruit and retain consumer representatives.

Further refinement of the program content and mode of delivery is warranted. Some participants did not commence or subsequently dropped out of the program because they perceived a personal lack of assertiveness to represent other consumers or ability to present an alternative view to a committee. Support for consumer representatives needs to explicitly address assertiveness and differentiate between 'rocking the boat' and advocating for woman-centred care. One of the most significant challenges consumer representatives face is being able to participate in nurturing, respectful and committed committees and groups. ${ }^{8}$ There is a significant need for health service committee members to also be supported to effectively work with their consumer representatives.

The MCRT program sought to recruit participants who could represent marginalised and vulnerable women, such as women from rural and remote Queensland, culturally and linguistically diverse women and Aboriginal and Torres Strait Island women. Consideration needs to be given to the best way to extend support to those groups of volunteers. The experience of conducting the workshop in a regional area (Cairns) highlighted the potential to create a strong local network. Taking the workshop to rural and remote areas could be part of building capacity among those consumers. Further 
Publisher: CSIRO; Journal: AH:Australian Health Review

Article Type: research-article; Volume: ; Issue: ; Article ID: AH13183

DOI: 10.1071/AH13183; TOC Head:

investigation is needed regarding the best ways to engage and support prospective cultural and linguistically diverse consumer representatives and Indigenous consumer representatives. Perhaps that investigation could involve the small number of culturally and linguistically diverse participants and Indigenous participants from this project in developing a workshop specifically for their communities.

The role of consumer organisations in supporting consumer representatives is vital, but also demanding. The sustainability and effectiveness of consumer representation goes hand-in-hand with the sustainability of consumer organisations. An underpinning principle of being a consumer representative is accountability to and nomination by an organisation of consumers. Through consumer organisations, consumer representatives may secure their 'representativeness' and, by extension, their legitimacy in the view of the health service. ${ }^{20}$ If the nominating consumer organisation has limited resources, it may be difficult for them to support, mentor, train and seek feedback about their consumer representative's work. The majority of maternity consumer organisations are focused on peer support, rather than consumer representation. Consideration needs to be given to creative ways to extend resources, including government funding, ${ }^{21}$ to consumer organisations to enable them to recruit, nominate and support consumer representatives.

The opportunity now exists to develop some specific support for committee chairs and committee members around the role and value of consumer representatives, as well as strategies for effective recruitment, retention and engagement of consumer representatives. Moreover, numerous inquiries were received from midwives and midwifery students, highlighting their interest in systems advocacy and the need to support them in being effective in such roles. Such work could be taken up by the professional colleges.

\section{Conclusions}

The MCRT program achieved its aim of building capacity among prospective consumer representatives by offering training to 58 participants from around Queensland. There is sufficient evidence from the evaluation to conclude that training for maternity consumer representatives is useful but strategies for ongoing support need to be investigated.

\section{Acknowledgements}

The authors acknowledge and thank the 55 people who participated in the Maternity Consumer Representative project and who volunteered their time to represent consumers of maternity services and work towards consumer-focused maternity care that is integrated, evidence based and provides optimal choices for women in Queensland. The authors also thank HCQ and the MC for their support of this project and consumer representation. In particular, the authors acknowledge the valuable contribution of Alison Gaffney and Paige Armstrong. The project was funded by Queensland Health through the QCMB. The QCMB is an independent research centre based at The University of Queensland in Brisbane. 


\section{References}

<eref>1 Australian Commission on Safety and Quality in Healthcare (ACSQHC). National safety and quality in health service standards. Sydney: ACSQHC; 2011. Available at:

http://www.safetyandquality.gov.au/publications/national-safety-and-quality-health-service-

standards/.</eref $>$

<eref>2 Hirst C. Re-birthing: report of the review of maternity services in Queensland. Brisbane:; 2005.

Available at:

http://www.health.qld.gov.au/publications/corporate/maternity_report2005/MaternityReview_Sec1.pdf.</eref $>$

<eref>3 Department of Health and Ageing. Improving maternity services in Australia: The Report of the maternity services review. Canberra: Commonwealth of Australia; 2009. Available at:

http://www.health.gov.au/internet/main/publishing.nsf/Content/maternityservicesreview-report [verified dd mmm yyyy].</eref>

<other>4 Cox D, Miller S, Tucker-Evans M, Kosky M. Consumer participation across Australia. Health Issues.

2009 (100): $11 .</$ other $>$

<bok>5 Pitkin HF. The concept of representation.: University of California Press; 1967.</bok>

<jrn>6 Nathan S, Johnston L, Braithwaite J. The role of community representatives on health service committees: staff expectations vs. reality. Health Expect 2011; 14: 272-84. doi:10.1111/j.1369$\underline{7625.2010 .00628 . x}</ j \mathrm{rn}>$

<jrn>7 Crawford MJ, Rutter D, Manley C, Weaver T, Bhui K, Fulop N, et al. Systematic review of involving patients in the planning and development of health care. BMJ 2002; 325: 1263.

doi:10.1136/bmj.325.7375.1263</jrn>

$<$ jrn>8 Nathan S, Harris E, Kemp L, Harris-Roxas B. Health service staff attitudes to community representatives on committees. J Health Organ Manag 2006; 20: 551-9. doi:10.1108/14777260610702299</jrn>

<jrn>9 Learmonth M, Martin GP, Warwick P. Ordinary and effective: the Catch-22 in managing the public voice in health care? Health Expect 2009; 12: 106-15. doi:10.1111/j.1369-7625.2008.00529.x</jrn>

$<$ jrn>10 Boote J, Telford R, Cooper C. Consumer involvement in health research: a review and research agenda. Health Policy 2002; 61: 213-36. doi:10.1016/S0168-8510(01)00214-7</jrn>

11 Oliver S, Clarke-Jones L, Rees R, Milne R, Buchanan P, Gabbay J, et al. Involving consumers in research and development agenda setting for the NHS: developing an evidence-based approach. Health Technol Assess 2004; 8: 1-148.

<jrn>12 Nilsen ES, Myrhaug HT, Johansen M, Oliver S, Oxman AD. Methods of consumer involvement in developing healthcare policy and research, clinical practice guidelines and patient information material. Cochrane Database Syst Rev 2006; 3: CD004563.</jrn> 
Publisher: CSIRO; Journal: AH:Australian Health Review

Article Type: research-article; Volume: ; Issue: ; Article ID: AH13183 DOI: 10.1071/AH13183; TOC Head:

<eref>13 International Association for Public Participation Australasia. IAP2 courses available. XXX:

International Association for Public Participation Australasia; 2013. Available at:

http://www.iap2.org.au/training/training [verified 24 September 2013].</eref>

<eref>14 Consumers Health Forum of Australia. Achieving good practice in consumer representation: response to the review of the Consumers Health Forum Consumer Representatives Program. Canberra: XXX; 2002. Available at: https://www.chf.org.au/rep-good-practice-consumer-representation-response.chf [verified dd mmm yyyy].</eref>

<eref>15 Consumers Health Forum of Australia. Consumer representatives workshop 14-15 August 2006 final report. Canberra: XXX; 2006. Available at: https://www.chf.org.au/rep-461-consumers-rep-workshop.chf [verified dd mmm yyyy].</eref>

<eref>16 Consumers Health Forum of Australia. Consumer representatives workshop 21-22 February 2005

final report. Canberra: XXX; 2005. Available at: https://www.chf.org.au/rep-338-consumer-rep-

workshop.chf [verified dd mmm yyyy].</eref $>$

<eref>17 Consumers Health Forum of Australia. Self-assessment for consumer representatives. Canberra:

Consumers Health Forum of Australia; 2006. Available at: https://www.chf.org.au/pdfs/crr/crr-self-

assessment-for-consumer-reps.pdf [verified dd mmm yyyy].</eref>

<bok>18 IBM SPSS Inc. PASW statistics, release version 18.0.3. Chicago, IL:; 2010.</bok>

<jrn>19 Nathan S, Braithwaite J, Stephenson N. Facilitating the action of community representatives in a health service: the role of a community participation coordinator. BMC Health Serv Res 2013; 13: 154. doi:10.1186/1472-6963-13-154</jrn>

<jrn>20 Nathan S, Stephenson N, Braithwaite J. Sidestepping questions of legitimacy: how community representatives manoeuvre to effect change in a health service. Health 2014, 18: 23-40.</jrn>

<bok>21 Draper M. Involving consumers in improving hospital care: lessons from Australian hospitals.

Canberra: Public Affairs, Parliamentary and Access Branch, Commonwealth Department of Health and

Family Services; 1997.</bok>

<jrn>22 Richardson A, Sitzia J, Cotterell P. 'Working the system'. Achieving change through partnership working: an evaluation of cancer partnership groups. Health Expect 2005; 8: 210-20. doi:10.1111/j.13697625.2005.00332.x $</ j \mathrm{jn}>$

Table 1. Participant characteristics

Data show percentages, with the number of subjects in each group in parentheses

\begin{tabular}{lc}
\hline Age (years) & \\
$<20$ & $1.8 \%(1)$ \\
$20-30$ & $20 \%(11)$ \\
$31-40$ & $49 \%(27)$ \\
$41-65$ & $25.4 \%(14)$ \\
Non-response & $3.6 \%(2)$ \\
Language spoken at home & \\
English & $94.5 \%(52)$ \\
Other & $5.5 \%(3)$ \\
\hline
\end{tabular}




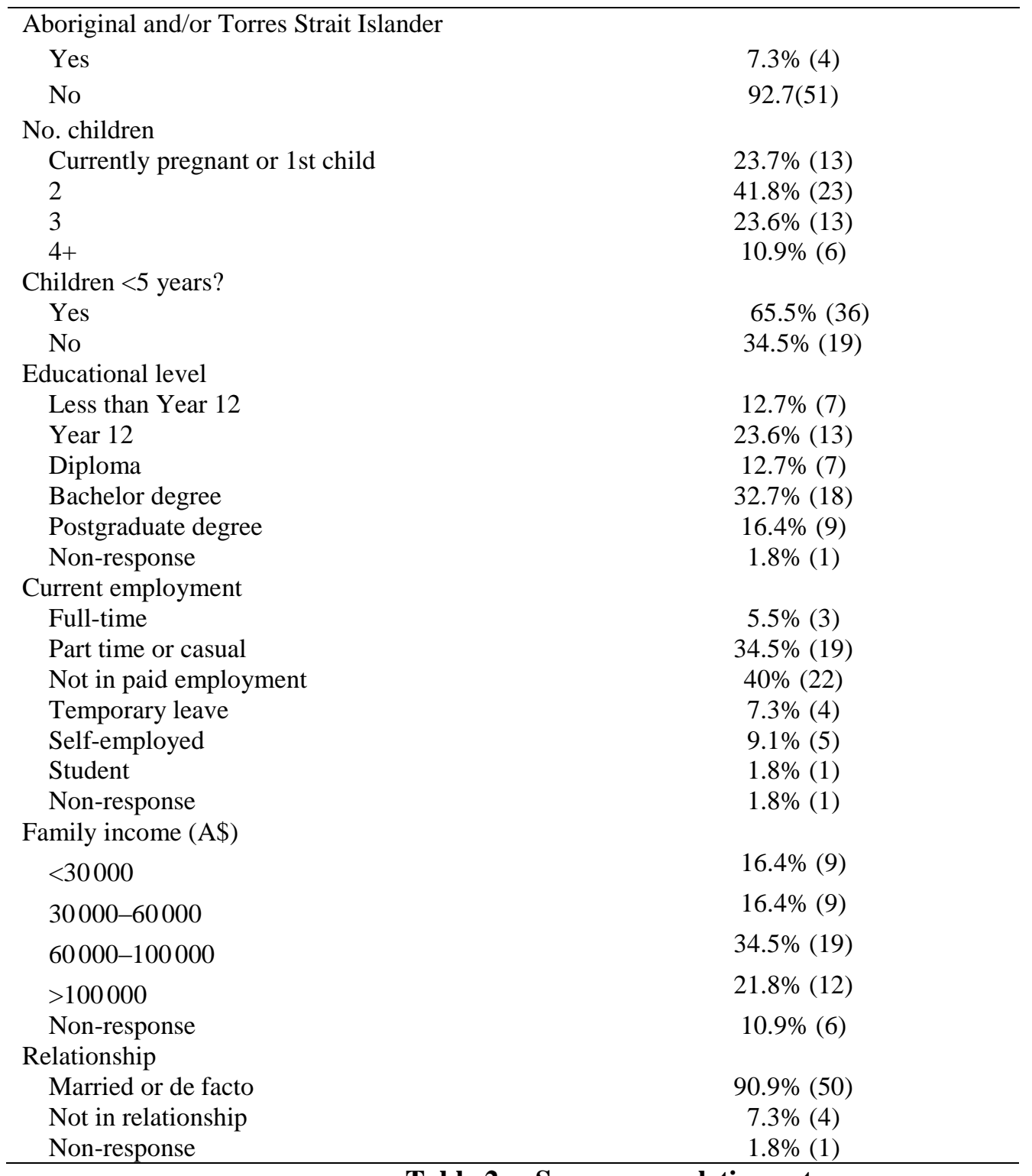

\section{Table 2. Survey completion rates}

Data show the number of completed surveys received, with percentages in parentheses. T1, Time 1;

T2, Time 2; T3, Time 3

\begin{tabular}{lcccc}
\hline Workshop & $\begin{array}{c}\text { Total } \\
\text { attendees }\end{array}$ & Pre-workshop (T1) & Post-workshop (T2) & $\begin{array}{c}\text { 3-Month follow-up } \\
\text { (T3) }\end{array}$ \\
\hline 1 & 26 & $26(100.0 \%)$ & $26(100 \%)$ & $15(57.7 \%)$ \\
2 & 17 & $16(94.1 \%)$ & $16(94.1 \%)$ & $10(58.8 \%)$ \\
3 & 15 & $14(93.3 \%)$ & $13(86.6 \%)$ & $5(33.3 \%)$ \\
\hline
\end{tabular}

Table 3. Perceptions of confidence across time

Confidence scale mean \pm s.d. scores

\begin{tabular}{lccc}
\hline Confidence subscale & $\begin{array}{c}\text { Pre-workshop } \\
\text { (T1) }\end{array}$ & $\begin{array}{c}\text { Post-workshop } \\
\text { (T2) }\end{array}$ & $\begin{array}{c}\text { 3-Month } \\
\text { follow-up (T3) }\end{array}$ \\
\hline 1. Role of a consumer representative & $3.94 \pm 0.43$ & $4.43 \pm 0.43$ & $4.01 \pm 0.47$ \\
2. Decision making & $3.73 \pm 0.53$ & $4.44 \pm 0.61$ & $3.79 \pm 0.70$ \\
3. Negotiating outcomes and liaising with key people & $3.76 \pm 0.44$ & $4.35 \pm 0.59$ & $3.78 \pm 0.61$ \\
4. Making use of relevant networks & $3.93 \pm 0.51$ & $4.56 \pm 0.44$ & $4.03 \pm 0.60$ \\
\hline
\end{tabular}


Publisher: CSIRO; Journal: AH:Australian Health Review Article Type: research-article; Volume: ; Issue: ; Article ID: AH13183 DOI: 10.1071/AH13183; TOC Head: 